\title{
The Relationship between China's Financial Industry Performance and Energy Elimination
}

\author{
Jun-Qi $\mathrm{Wu}^{1}$, Li-Chen $\mathrm{Chou}^{2, *}$ \\ ${ }^{1}$ Department of Finance, Wenzhou Business College, China \\ ${ }^{2}$ Department of Economics, Wenzhou Business College, China
}

\begin{abstract}
Taking the provinces, autonomous regions and cities in mainland China as the research objects, this paper collects and collates the data of production, input and energy consumption of the financial industry from 2009 to 2014, and analyzes the production efficiency of each region. The empirical results show that the production efficiency of all prefecturelevel cities is 0.782 . If analysed on region basis, the average production efficiency of prefecture-level cities is the highest in the eastern provinces, followed by the central provinces and the lowest in the western provinces. If analysed on annual basis, the distribution of production efficiency shows a trend of decline during 2009-2010 and increase after 2012.
\end{abstract}

\section{Introduction}

Since the 1980s, China has experienced 40 years of high economic growth, during which time China's economic output has increased year by year. Income per capita, living environment and consumption scale also increase as a result of sustained economic growth. However, with a long period of rapid growth, China's economy has also encountered problems, including slowdown in economic growth and greenhouse gases negatively affecting environment during the pursuit of economic production. Moreover, as China's economy progresses into transition stage, the overall proportion of first, second and tertiary industries contributing to the economy has grown unbalanced year by day. In the course of such a transformation, the relationship between China's economic performance and energy consumption has gradually been emphasized by the academic community. In conclusion, the influence and contribution of the financial industry has become increasingly important to China's economy during the transition stage. Since the Kyoto Protocol was introduced in 1995, the academic and practice communities have begun to discuss the influence of financial or other industries to energy consumption, greenhouse gas emission reduction, and to the development of green finance.

Green Finance has two aspects of meanings: first, environmental protection factors are regarded as the focus and even center of business during financial supervision policy formulation and financial institutions' operation business activities, in order to strengthen the coordination of financial and industrial policies, and integrate the benefits, risks and costs related to environmental protection with the business. The government should strictly

* Corresponding author: edcv2581013@gmail.com 
control financial support to enterprises with high energy consumption and pollution and environmental illegal enterprises, guide funds into green industries such as energy-saving technology, ecological protection and pollution control, and allocate social and economic resources, thereby promoting sustainable development of society through financial leverage. In short, green finance is to solve financing difficulties and financing problems for green projects, while making pollution projects difficult and expensive to finance. Second, Green Finance means the sustainable development of financial industry itself. Green Finance mentioned in this paper mainly refers to the first meaning.

Today, a series of environmental problems, such as global warming and animal extinction, have forced people to turn to low-carbon energy sources to prevent catastrophic consequences. However, the prices of traditional energy sources, such as coal oil, have been falling all the way, threatening the development solar energy and wind energy as well. Obviously, the development of low-carbon economy has been an irresistible trend in the post-crisis era. Natural gas has been widely used in America and the Clean Atmosphere Act has been introduced to set standards for a corresponding strict coal environment, which has increased the cost of coal power stations, forcing many thermal power stations to shut down. Nevertheless, from a world perspective, with the exception of the United States, which has largely exploited green energy, coal power generation in many emerging countries, such as India, remains the cheapest way to acquire energy sources. Therefore, preventing global warming is only a problem for scientists, but also requires innovation in global green finance. Finance plays an important role in economic development. China has begun to restrict coal consumption and lay natural gas pipelines in recent years. However, China is still in the primary stage of green finance development. Green credit, carbon finance and other representative green finance development is immature.

This paper intends to apply China Urban Statistics Yearbook, taking 288 Chinese cities as research subjects to discuss the relationship between urban financial industry performance and energy elimination between 2009 and 2014. Table 1 collates relevant statistical variables as follows. It can be observed that during the production process of financial industry, the proportion of capital investment is relatively larger than human resource input.

Table 1. Descriptive statistics.

\begin{tabular}{|c|c|c|c|c|}
\hline Variable & $\mathbf{m m}$ & $\begin{array}{c}\text { Standard } \\
\text { deviation }\end{array}$ & $\begin{array}{c}\text { Minimum } \\
\text { value }\end{array}$ & $\begin{array}{c}\text { Maximum } \\
\text { value }\end{array}$ \\
\hline $\begin{array}{c}\text { Financial industry } \\
\text { yield (Y) }\end{array}$ & 8502478 & 9188921 & 200740 & 68928296 \\
\hline Industrial labor (L) & 227701 & 283797 & 4300 & 2975900 \\
\hline $\begin{array}{c}\text { Industrial capital } \\
\text { investment (K) }\end{array}$ & 7797784 & 12605010 & 123588 & 96510872 \\
\hline $\begin{array}{c}\text { Electricity } \\
\text { consumption (E) }\end{array}$ & 485635 & 668286 & 454 & 5195783 \\
\hline
\end{tabular}

Resources Source: collation of this paper research.

\section{Literature, methodology and empirical results}

\subsection{Literature}

Feng and Li (2010) analysed different economic efficiency of 21 prefecture-level cities in Sichuan province during 2000-2008, using the DEA method. It is found that the distribution 
of technical efficiency in Sichuan province is uneven. The main reason for this imbalance is that Sichuan's economic development is based on the so-called 'high investment, low efficiency' model. One-step stochastic frontier analysis and two-step meta-frontier model are used by Chen et al. [1] to investigate the productivity of coastal and non-coastal regions in Mainland China from 2000 to 2010. The results show that the coastal region has better production performance.

\subsection{Methodology}

The model is set as follows:

$$
\ln \mathrm{Y}_{\mathrm{i}}=\mathrm{X}_{\mathrm{i}}{ }_{\mathrm{B}} \mathrm{B}+\mathrm{v}_{\mathrm{i}}-\mathrm{u}_{\mathrm{i}}
$$

$\mathrm{Y}$ and $\mathrm{X}$ respectively represent producer's output and input or other factors and explanatory variables that can influence output. $\mathrm{v}_{\mathrm{i}}$ represents uncontrollable random factors. $\mathrm{u}_{\mathrm{i}}$ represents the part that can be controlled by manufacturers or decision makers themselves but unable to achieve efficiency. These two factors are independent of each other. Under this setting, the output value is qualified to be higher than the random variable $\exp \left(\mathrm{X}_{\mathrm{i}}{ }_{\mathrm{B}} \mathrm{B}+\mathrm{v}_{\mathrm{i}}\right)$. Random variables can be positive or negative, and their output patterns change with the deterministic $\operatorname{part} \exp \left(\mathrm{X}^{\prime}{ }_{\mathrm{i}} \mathrm{B}\right)$.

Empirical estimates indicate that stochastic frontier uses statistical most likelihood function estimation method to calculate. The definition estimator formula is:

$$
\begin{aligned}
& \ln Y_{\mathrm{i}}=\mathrm{X}^{\prime}{ }_{\mathrm{i}} \mathrm{B}+\mathrm{v}_{\mathrm{i}}-\mathrm{u}_{\mathrm{i}}, \mathrm{i}=1, \ldots, \mathrm{I} \\
& \mathrm{v}_{\mathrm{i}} \sim \mathrm{N}^{+}\left(0, \sigma^{2}{ }_{\mathrm{v}}\right), \mathrm{u}_{\mathrm{i}} \sim \mathrm{N}^{+}\left(0, \sigma^{2}{ }_{\mathrm{u}}\right), \mathrm{f}(\mathrm{u})=\left\{2 /\left[(2 \pi)^{0.5} \sigma_{\mathrm{u}}\right\} \exp \left\{-\mathrm{u}^{2} / 2 \sigma^{2}{ }_{\mathrm{u}}\right\}, \mathrm{u} \geq 0\right.
\end{aligned}
$$

As mentioned earlier, $v_{i}$ in formula (2) is a measurement inefficiency term and has identically distributed normal random variables. The average value is 0 . The variance is $\sigma_{\mathrm{v}}^{2}$. The characteristic $u_{i}$ is a random variable that obeys the semi-normal and $\sigma^{2}$ variance of the statistical distribution.

\subsection{Empirical results}

Table 2 summarizes the productivity changes of regions in China, based on the estimation of formula (1) and formula (2). The table shows that prefecture-level cities in Inner Mongolia Autonomous Region have the highest average production efficiency, followed by Jilin Province. Hainan Province and Tibet Autonomous Region have the lowest average production efficiency. If analysed on annual basis, the regions and provinces with the best average production efficiency are Inner Mongolia, Henan, Jilin. Hainan, Qinghai, and Tibet have a relatively poor performance, while the production efficiency of Qinghai Province has improved significantly since 2012. If analysed on region basis, the production efficiency of all prefecture-level cities is 0.782 . To be more specific, the average production efficiency of prefecture-level cities is the highest in the eastern provinces, followed by the central provinces and the lowest in the western provinces. Secondly, from the changes over the years, it can be observed that the distribution pattern of production efficiency in various regions basically declines at first and then increases. The production efficiency of eastern and western provinces started to decline respectively since 2010 . The production efficiency of central Provinces decreased since 2009, while has gradually increased since 2013.

Table 2. The average production efficiency of financial industry in China's provinces and autonomous regions. 


\begin{tabular}{|c|c|c|c|c|c|c|c|}
\hline Province & $\begin{array}{c}\text { Mean } \\
\text { value }\end{array}$ & $\mathbf{2 0 0 9}$ & $\mathbf{2 0 1 0}$ & $\mathbf{2 0 1 1}$ & $\mathbf{2 0 1 2}$ & $\mathbf{2 0 1 3}$ & $\mathbf{2 0 1 4}$ \\
\hline Shanxi & 0.712 & 0.734 & 0.670 & 0.723 & 0.713 & 0.730 & 0.702 \\
\hline Shandong & 0.825 & 0.826 & 0.854 & 0.817 & 0.815 & 0.812 & 0.829 \\
\hline Inner Mongolia & 0.857 & 0.838 & 0.881 & 0.852 & 0.860 & 0.853 & 0.861 \\
\hline Sichuan & 0.796 & 0.794 & 0.756 & 0.810 & 0.815 & 0.792 & 0.810 \\
\hline Gansu & 0.704 & 0.732 & 0.719 & 0.722 & 0.722 & 0.669 & 0.661 \\
\hline Jilin & 0.852 & 0.828 & 0.847 & 0.862 & 0.867 & 0.854 & 0.852 \\
\hline Anhui & 0.759 & 0.770 & 0.784 & 0.764 & 0.682 & 0.758 & 0.792 \\
\hline Jiangxi & 0.783 & 0.798 & 0.801 & 0.811 & 0.713 & 0.782 & 0.794 \\
\hline Jiangsu & 0.827 & 0.829 & 0.862 & 0.836 & 0.842 & 0.790 & 0.803 \\
\hline Tibet & 0.513 & 0.683 & N.A & N.A & 0.484 & 0.521 & 0.364 \\
\hline Hebei & 0.797 & 0.804 & 0.781 & 0.806 & 0.794 & 0.794 & 0.802 \\
\hline Henan & 0.823 & 0.837 & 0.822 & 0.836 & 0.829 & 0.805 & 0.809 \\
\hline Qinghai & 0.623 & 0.477 & 0.673 & 0.497 & 0.492 & 0.707 & 0.713 \\
\hline Hainan & 0.564 & 0.570 & 0.609 & 0.557 & 0.586 & 0.520 & 0.541 \\
\hline Zhejiang & 0.719 & 0.696 & 0.778 & 0.703 & 0.682 & 0.720 & 0.733 \\
\hline Shanxi & 0.816 & 0.803 & 0.753 & 0.826 & 0.836 & 0.832 & 0.843 \\
\hline Hubei & 0.786 & 0.783 & 0.742 & 0.799 & 0.800 & 0.793 & 0.801 \\
\hline Hunan & 0.830 & 0.821 & 0.790 & 0.834 & 0.839 & 0.841 & 0.856 \\
\hline Guizhou & 0.718 & 0.660 & 0.732 & 0.710 & 0.706 & 0.727 & 0.756 \\
\hline Yunnan & 0.704 & 0.691 & 0.745 & 0.660 & 0.687 & 0.709 & 0.735 \\
\hline Heilongjiang & 0.756 & 0.763 & 0.706 & 0.781 & 0.781 & 0.771 & 0.731 \\
\hline Xinjiang & 0.776 & 0.749 & 0.811 & 0.781 & 0.780 & 0.763 & 0.772 \\
\hline Ningxia & 0.728 & 0.688 & 0.790 & 0.707 & 0.711 & 0.726 & 0.746 \\
\hline Fujian & 0.754 & 0.727 & 0.807 & 0.736 & 0.718 & 0.755 & 0.782 \\
\hline Guangxi & 0.812 & 0.800 & 0.820 & 0.808 & 0.807 & 0.806 & 0.830 \\
\hline Guangdong & 0.796 & 0.815 & 0.777 & 0.811 & 0.804 & 0.774 & 0.793 \\
\hline Liaoning & 0.784 & 0.769 & 0.779 & 0.788 & 0.796 & 0.792 & 0.781 \\
\hline
\end{tabular}

Table 3 shows further evaluation of relationship between economic performance and energy consumption in the financial industry, using the correlation matrix. It can be found from the table that there is a significant positive correlation between the output value of financial industry and energy consumption. The results show that there is a certain degree of correlation between the development of financial industry and the current energy consumption in China.

Table 3. Correlation matrix.

\begin{tabular}{|c|c|c|c|c|}
\hline Variable name & $\begin{array}{c}\text { Financial } \\
\text { industry yield }\end{array}$ & $\begin{array}{c}\text { Industrial } \\
\text { labor }\end{array}$ & $\begin{array}{c}\text { Industrial } \\
\text { capital } \\
\text { investment }\end{array}$ & $\begin{array}{c}\text { Electricity } \\
\text { consumption }\end{array}$ \\
\hline $\begin{array}{c}\text { Financial industry } \\
\text { yield }\end{array}$ & 1 & 1 & & \\
\hline Industrial labor & $0.8429 * * *$ & $0.8464 * * *$ & 1 & 1 \\
\hline $\begin{array}{c}\text { Industrial capital } \\
\text { investment }\end{array}$ & $0.8737 * * *$ & $0.6489 * * *$ & $0.6566^{* * *}$ & 1 \\
\hline $\begin{array}{c}\text { Electricity } \\
\text { consumption }\end{array}$ & $0.7482 * * *$ & & & \\
\hline
\end{tabular}

\section{Conclusion}

This paper uses the prefecture-level cities in the provinces and autonomous regions of mainland China as the research object to collect and collate the relevant financial industry production, input and energy consumption data in 6 years during 2009-2014, and analyze 
the production efficiency of each region. The biggest difference between this paper and the past literature is that past studies on production performance and efficiency mainly discuss from the perspective of provinces, municipalities or specific areas and regions. This study takes the national prefecture-level cities as the research object, and analyse the city production performance and energy efficiency changes in different years.

The empirical results show that the production efficiency of all prefecture-level cities is 0.782. If analysed on region basis, the average production efficiency of prefecture-level cities is the highest in the eastern provinces, followed by the central provinces and the lowest in the western provinces. If analysed on annual basis, the distribution of production efficiency shows a trend of decline during 2009-2010 and increase after 2012. Secondly, there is a negative correlation between production performance and energy efficiency. Last but not least, from the perspective of areas and regions, the evaluation of efficiency reflects the differences of production performance between regions in China. In recent years, the mean value of eastern and central regional cities has grown closer, while there is still room for improvement in the average efficiency mean of western provinces. Policy makers should effectively improve the performance and efficiency of the regional cities through making economic strategies and upgrading production technology upgrading. The difference of inter-regional efficiency is similar to the current regional economic development in China. If we can effectively improve the production performance and energy efficiency of prefecture-level cities in the western provinces with relevant economic and industrial policies, and narrow the gap between western and eastern provinces, we may improve the current situation of imbalanced economic development in China.

\section{References}

1. C. Y. Chen, S. H. Lin, L. C. Chou, K. D. Chen, The Journal of International Trade \& Economic Development, 27(8), 901-916, (2018)

2. Lin, B., K. Du, Energy Economics, 40, 529-536, (2013)

3. Shi, G. M., J. Bi, and J. N. Wang, Energy Policy, 38, 6172-6179, (2010)

4. Wang, Q. W., P. Zhou, and D. Q. Zhou, Applied Energy, 90(1), 161-166, (2012)

5. Wang, Q. W., P. Zhou, and D. Q. Zhou, Economic Modelling, 35(5), 283-289, (2013)

6. Wei Y. M., H. Liao, and Y. Fan, Energy, 32(12), 2262-2270, (2007)

7. Wu, F., L. W. Fan, P. Zhou, and D. Q. Zhou, Energy Policy, 49(1), 164-172, (2012)

8. Zhang, N. and Y. Choi, The Social Science Journal, 50(2), 225-234, (2013) 